\title{
Assessing Static Performance of the Dashengguan Yangtze Bridge by Monitoring the Correlation between Temperature Field and Its Static Strains
}

\author{
Gao-Xin Wang, ${ }^{1,2}$ You-Liang Ding, ${ }^{1,2}$ Peng Sun, ${ }^{3}$ Lai-Li Wu, ${ }^{4}$ and Qing Yue ${ }^{4}$ \\ ${ }^{1}$ The Key Laboratory of Concrete and Prestressed Concrete Structures of Ministry of Education, Southeast University, \\ Sipailou Road, Xuanwu District, Nanjing, Jiangsu 210096, China \\ ${ }^{2}$ Department of Civil Engineering, Southeast University, Sipailou Road, Xuanwu District, Nanjing, Jiangsu 210096, China \\ ${ }^{3}$ Department of Civil and Environmental Engineering, Rice University, Houston, TX 77005, USA \\ ${ }^{4}$ China Railway Major Bridge (Nanjing) Bridge and Tunnel Inspect \& Retrofit Co., Ltd., Nanjing 210032, China
}

Correspondence should be addressed to You-Liang Ding; civilchina@hotmail.com

Received 30 August 2014; Accepted 9 October 2014

Academic Editor: Ting-Hua Yi

Copyright (c) 2015 Gao-Xin Wang et al. This is an open access article distributed under the Creative Commons Attribution License, which permits unrestricted use, distribution, and reproduction in any medium, provided the original work is properly cited.

Taking advantage of the structural health monitoring system installed on the steel truss arch girder of Dashengguan Yangtze Bridge, the temperature field data and static strain data are collected and analyzed for the static performance assessment of the bridge. Through analysis, it is found that the static strain changes are mainly caused by temperature field (temperature and temperature difference) and train. After the train-induced static strains are removed, the correlation between the remaining static strains and the temperature field shows apparent linear characteristics, which can be mathematically modeled for the description of static performance. Therefore, multivariate linear regression function combined with principal component analysis is introduced to mathematically model the correlation. Furthermore, the residual static strains of mathematical model are adopted as assessment indicator and three kinds of degradation regulations of static performance are obtained after simulation of the residual static strains. Finally, it is concluded that the static performance of Dashengguan Yangtze Bridge was in a good condition during that period.

\section{Introduction}

In recent years, with development of the structural health monitoring technology, it is feasible to install sensors for monitoring the performance of bridge structures [1-4]. Static strain effect caused by combined load actions such as temperature field and traffic loading can present static performance of bridge structures [5-7]. Relevant research showed that daily or seasonal temperature field caused critical strain levels, even higher than traffic-induced strains [8], so abnormal variation of correlation between temperature field and its static strain effect can indicate static performance degradation of bridge structures. For example, Duan et al. developed linear regression models for structural performance evaluation using temperature-strain correlation [8]; Li et al. obtained probability models for performance assessment application on cable stayed bridges through statistical analysis of temperature-strain linear relationships [9]. However, current research efforts in this field are still insufficient in many specific details: (1) current research interests merely focus on correlation between temperature and static strain and have not considered the influence of temperature difference on static strain; (2) current research methods merely concentrate on single variable analysis, whereas static strain from one monitoring point is actually influenced by both temperature and temperature difference from many different monitoring points; (3) current research progress has not definitely pointed out degradation regulations of static performance when correlation between temperature field and its static strain effect abnormally changes.

Therefore, using health monitoring system installed on steel truss arch girder of the Dashengguan Yangtze Bridge, 


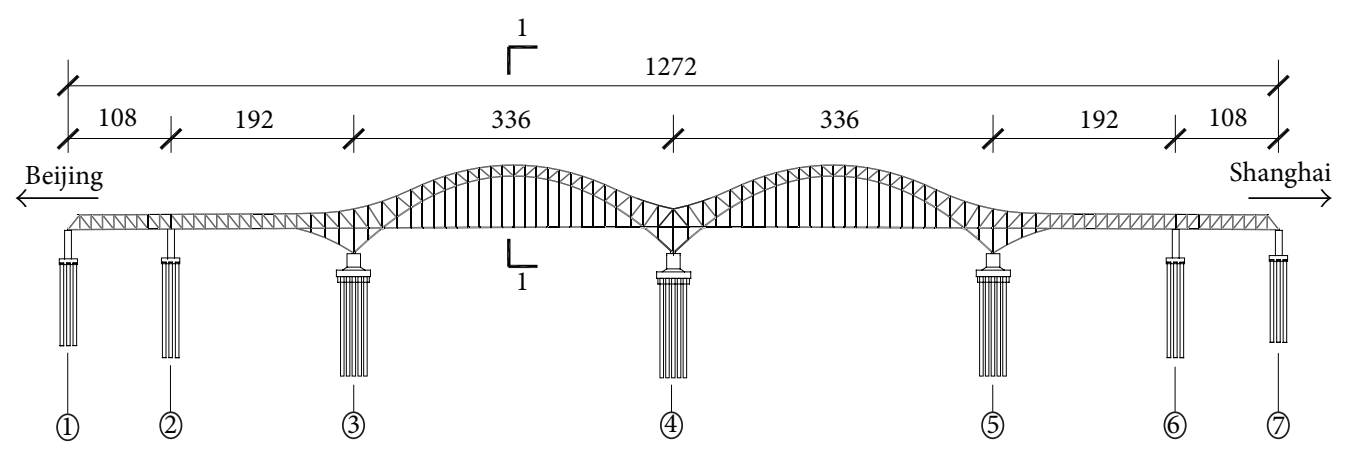

Figure 1: Longitudinal structural type of the Dashengguan Yangtze Bridge (unit: m).

temperature field data and static strain data from top chord member, arch rib chord member, bottom chord member, and diagonal web member are continuously collected, and then variation regularities of their time history curves are analyzed by comparison. Wavelet packet decomposition method is introduced to extract static strains caused by temperature and temperature difference data and then principal component analysis is carried out to simplify the multivariate linear regression model. Finally, three kinds of degradation regulations of residual static strains are put forward to assess static performance of the Dashengguan Yangtze Bridge.

\section{Bridge Health Monitoring and Data Collection}

2.1. Bridge Health Monitoring. The bridge monitoring object for this research is the famous Dashengguan Yangtze Bridge, which is designed as the river-crossing channel for the Beijing-Shanghai high speed railway and Nanjing bidirectional subway. The structural type of its main girder is the continuous steel truss arch girder with the main span reaching $336 \mathrm{~m}$ as shown in Figure 1 . According to its 1-1 profile as shown in Figure 2(a), the continuous steel truss arch girder is composed of steel truss arch and steel bridge deck. Moreover, the steel truss arch comprises chord members with box-shaped cross-sections (top chord, arch rib chord, and bottom chord, resp.), diagonal web members with I-shaped cross-sections, vertical web members, and horizontal and vertical bracings as shown in Figures 2(a) and 2(b); the steel bridge deck comprises top plate and transverse stiffening girder as shown in Figure 2(a).

In order to get the variation regularity of temperature field in steel truss arch girder, eight FBG temperature sensors are installed on the cross-sections of top chord member, diagonal web member, arch rib chord member, and bottom chord member, respectively, as shown in Figures 2(c) 2(f) (where $W_{i}$ denotes the $i$ th temperature sensor, $i=1,2, \ldots, 8$ ) to continuously measure temperature field data. Besides, eight FBG strain sensors are installed on the same positions with temperature sensors as shown in Figures 2(c) 2(f) respectively (where $Y_{i}$ denotes the $i$ th strain sensor, $i=$ $1,2, \ldots, 8)$, to continuously obtain axial static strain data. Sampling frequency of data collection is set to $1 \mathrm{~Hz}$, which is appropriate since the changes of temperature and strain are very slow and little.

2.2. Data of Temperature Field and Static Strains. Data of temperature field and static strains in certain months are specially chosen: (1) data from March 2013 to October 2013 are chosen as training data for modeling the correlation; (2) data in November 2013 are chosen as test data for testing the modeling effectiveness; (3) data from March 1st, 2014, to March 19th, 2014, are chosen as assessment data for evaluating the static performance. Temperature data from temperature sensor $W_{i}$ is denoted by $T_{i}$, temperature difference data acquired by $T_{i}$ minus $T_{j}$ is denoted by $T_{i j}$, and static strain data from strain sensor $Y_{i}$ is denoted by $S_{i}(i, j=1,2, \ldots, 8)$. The history curves of global change and daily change in temperature data and temperature difference data, taking $T_{1}$ and $T_{12}$ from training data, for example, are shown in Figures 3 and 4, respectively. The history curves of global change and daily change in static strain data, taking $S_{1}$ and $S_{2}$ from training data, for example, are shown in Figures 5 and 6 , respectively (negative values denote compressive static strain and positive values denote tension static strain).

From Figures 3 to 6 , some findings can be obtained: (1) the history curves of global change and daily change in static strain data $S_{1}$ are similar to that of temperature difference data $T_{12}$ shown in Figures 4 and 5; that is, the global curves of $S_{1}$ and $T_{12}$ are both stationary and the daily curves of $S_{1}$ and $T_{12}$ both change little at night and change obviously at daytime in wave shape simultaneously, indicating that static strain data $S_{1}$ mainly vary with temperature difference; (2) the history curves of global change and daily change in static strain data $S_{2}$ are similar to that of temperature data $T_{1}$ shown in Figures 3 and 6; that is, the global curves of $S_{2}$ and $T_{1}$ are both seasonable and the daily curves of $S_{2}$ and $T_{1}$ both change in the shape of one-cycle sine curve, indicating that static strain data $S_{2}$ mainly vary with temperature; (3) daily history curves of $S_{1}$ and $S_{2}$ contain many sharp peaks caused by trains as shown in Figures 5(b) and 6(b), with each peak corresponding to the time when one train is across the bridge, whereas the proportion of its influence on static strain is obviously lower than that of temperature and temperature difference. 


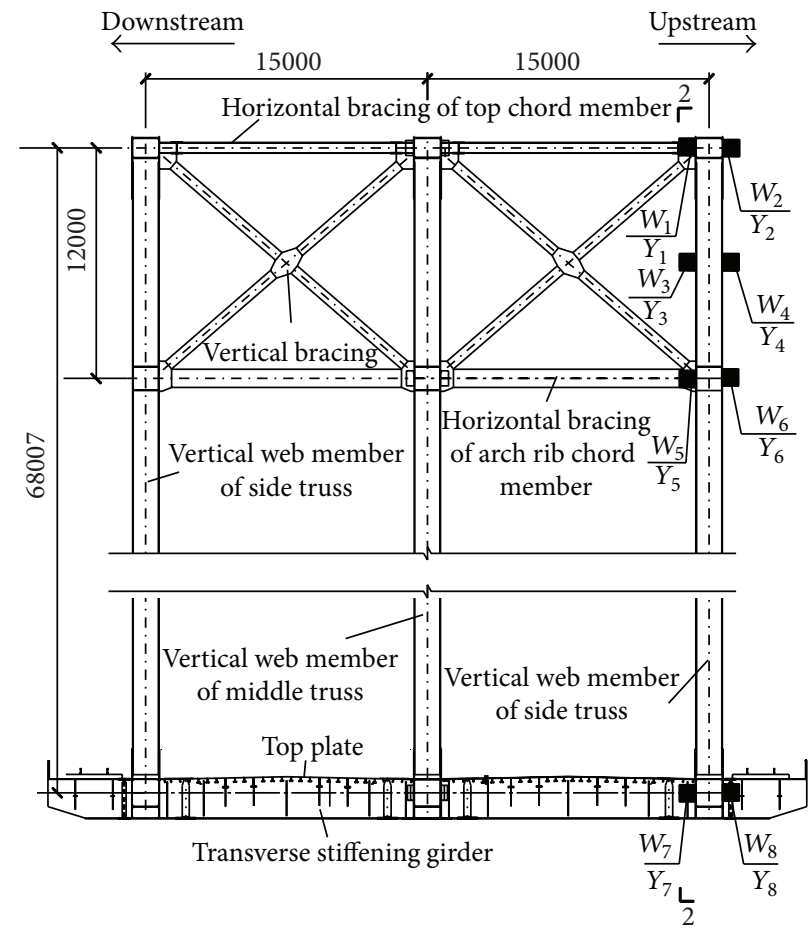

(a) 1-1 profile of steel truss arch girder

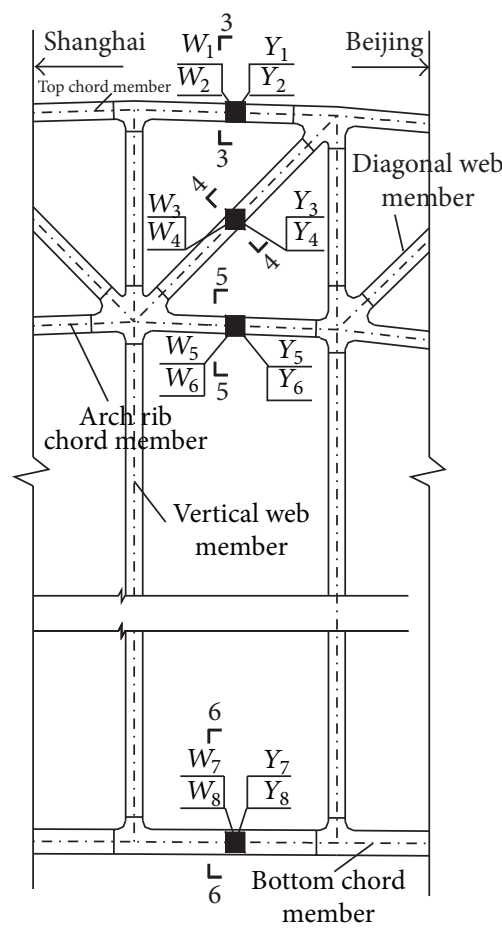

(b) 2-2 profile of steel truss arch

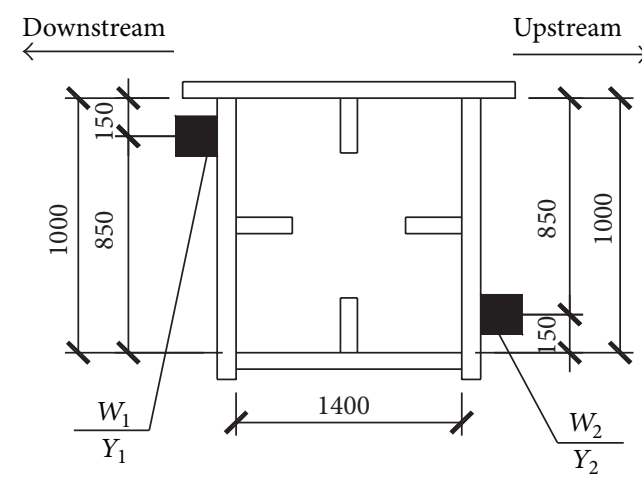

(c) 3-3 profile of top chord member

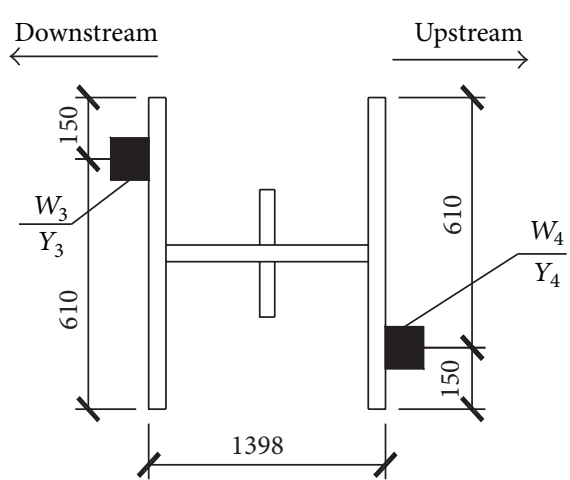

(d) 4-4 profile of diagonal web member

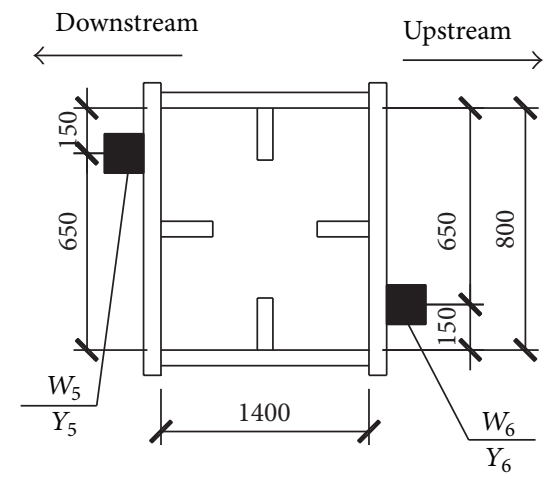

(e) 5-5 profile of arch rib chord member

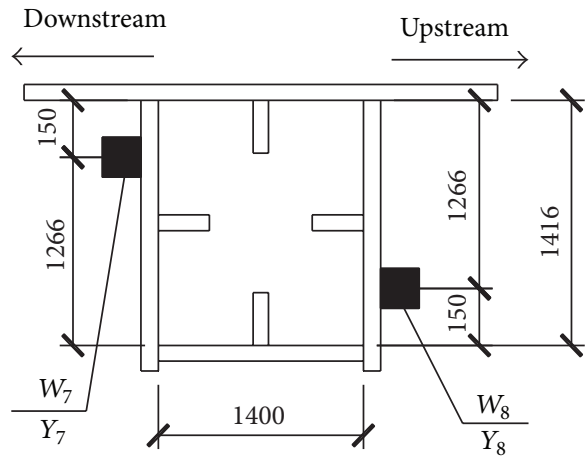

(f) 6-6 profile of bottom chord member

FIGURE 2: Layout of temperature and strain sensors on the steel truss arch girder (unit: $\mathrm{mm}$ ). 


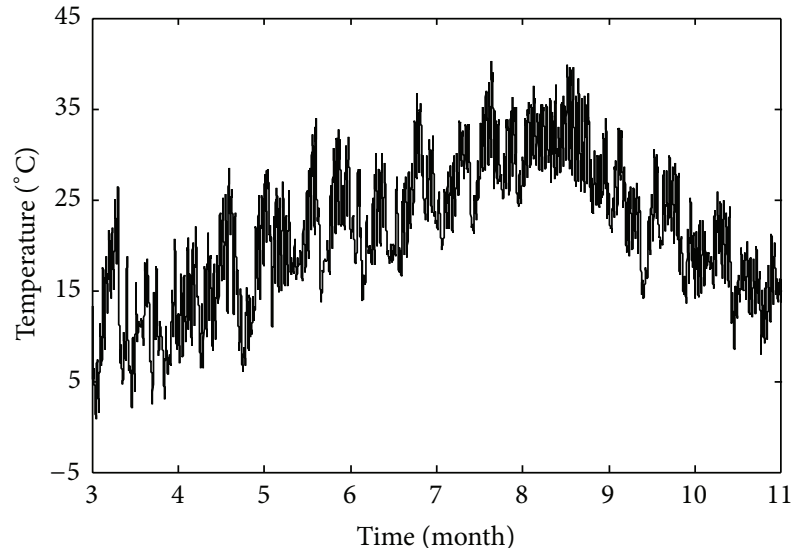

(a) Global history curve

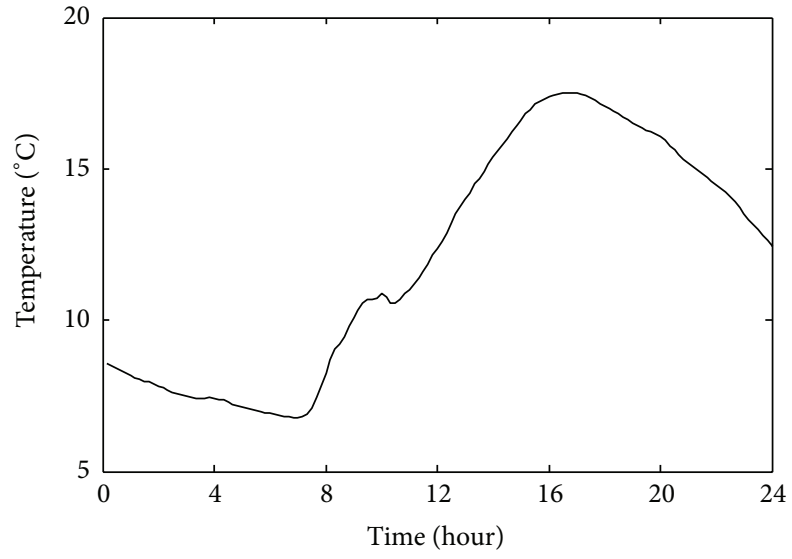

(b) Daily history curve (March 4th, 2013)

FIGURE 3: History curves of global change and daily change in temperature data $T_{1}$.

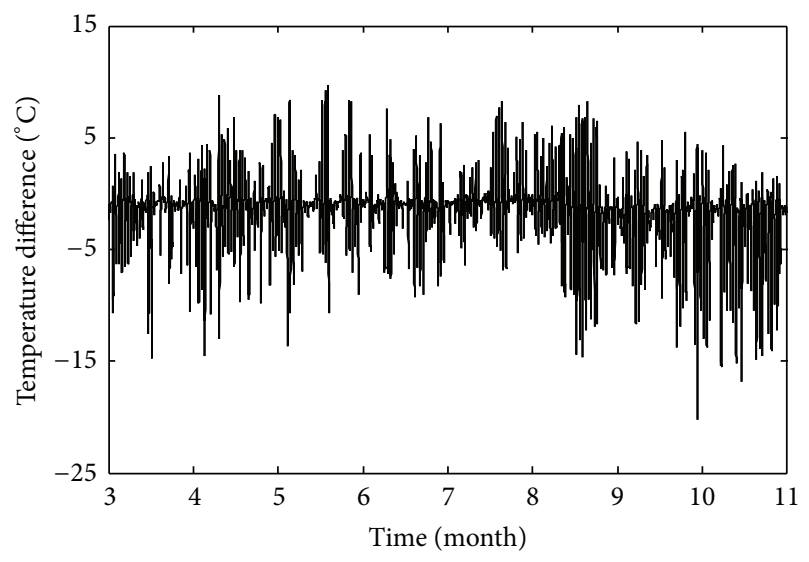

(a) Global history curve

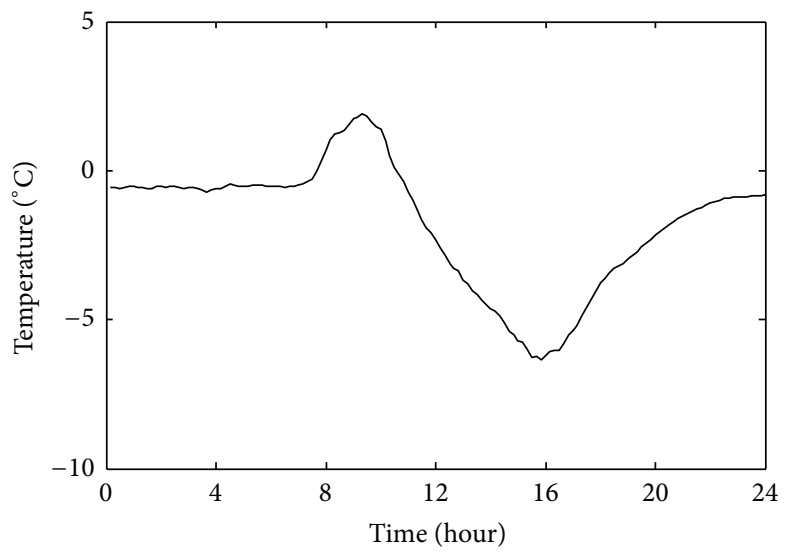

(b) Daily history curve (March 4th, 2013)

FIGURE 4: History curves of global change and daily change in temperature difference data $T_{12}$.

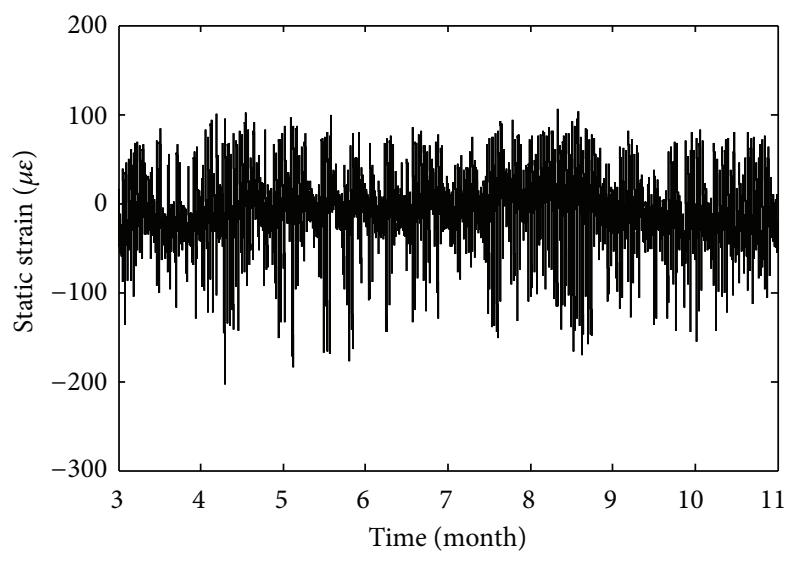

(a) Global history curve

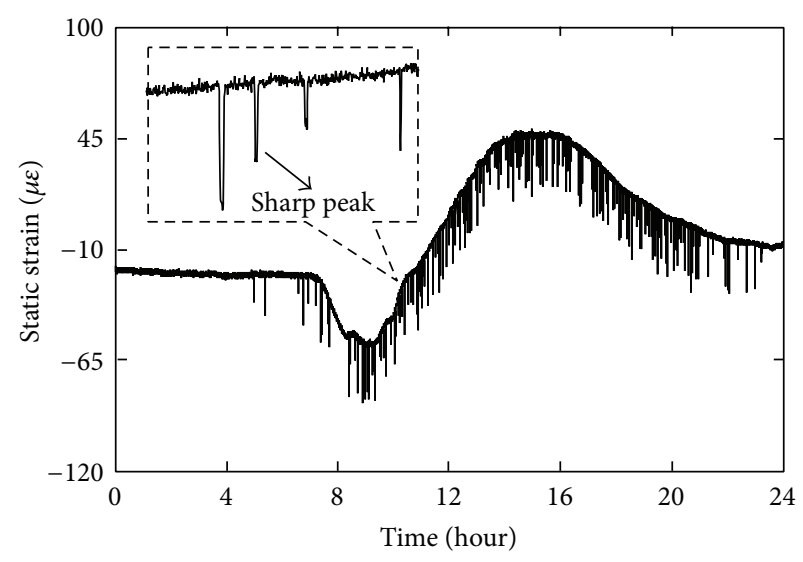

(b) Daily history curve (March 4th, 2013)

FIGURE 5: The history curves of global change and daily change in static strain data $S_{1}$. 


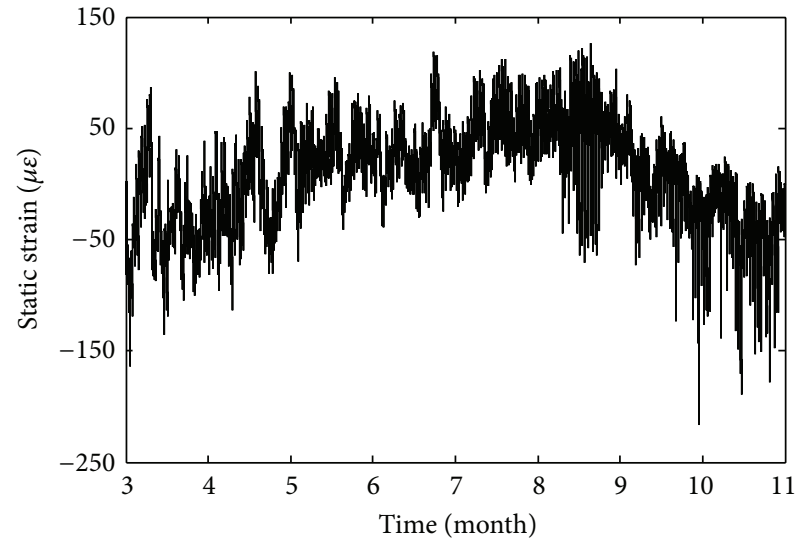

(a) Global history curve

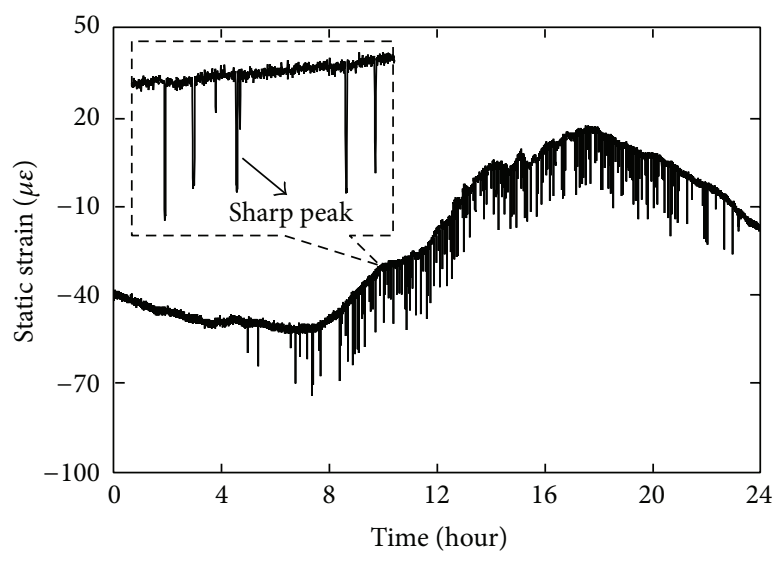

(b) Daily history curve (March 4th, 2013)

FIGURE 6: History curves of global change and daily change in static strain data $S_{2}$.

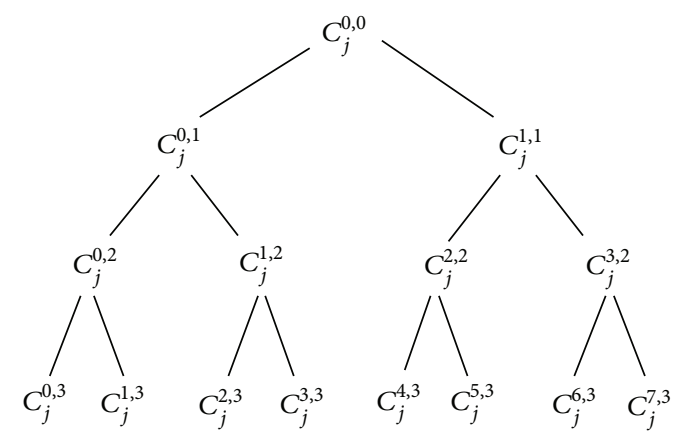

FIGURE 7: The hierarchical tree of decomposition coefficients in three scales.

\section{Correlation Analysis}

3.1. Extracting Static Strain Caused by Temperature Field. According to the analysis above, static strain data mainly contains three parts: static strain I caused by temperature, static strain II caused by temperature difference, and static strain III caused by train. In order to research the correlation between temperature field and its static strain effect, static strain I and static strain II (denoted by $S_{\text {I,II }}$ ) must be extracted from the static strain data. Considering that primary period of $S_{\text {I,II }}$ is one day, which is far longer than that of static strain III, wavelet packet decomposition method is introduced to extract $S_{\mathrm{I}, \mathrm{II}}$.

In detail, based on a pair of low-pass and high-pass conjugate quadrature filters $h(j)$ and $g(j)$ of wavelet packet, static strain data can be decomposed scale by scale into different frequency bands, and each decomposition coefficient corresponding to its frequency band and its scale is calculated as follows $[10,11]$ :

$$
\begin{aligned}
C_{j}^{k, 2 l} & =\sum_{m \in Z} C_{m}^{k+1, l} h(m-2 j) \\
C_{j}^{k, 2 l+1} & =\sum_{m \in Z} C_{m}^{k+1, l} g(m-2 j) .
\end{aligned}
$$

$C_{j}^{k, 2 l}$ or $C_{j}^{k, 2 l+1}$ denotes the decomposition coefficient within the $k$ th frequency band and the $2 l$ th or $(2 l+1)$ th scale, respectively, which is visually described by a hierarchical tree shown in Figure 7 (only three scales are listed). Each decomposition coefficient can be reconstructed into time-domain signals with constraints of its own frequency band; therefore decomposition coefficients within primary frequency band of $S_{\text {I,II }}$ can be specially selected and then reconstructed as $S_{\mathrm{I}, \mathrm{II}}$.

Taking the daily history curve of static strain data $S_{1}$ in Figure 5(b) as an example, it is decomposed within 8 scales and the decomposition coefficient $C_{j}^{0,8}$ is specially selected and then reconstructed as $S_{\text {I,II }}$ shown in Figure 8(a), which effectively retains main component caused by temperature field and removes sharp peaks caused by trains as well. Using the method above, $S_{\text {I,II }}$ of each static strain data is extracted, such as the extraction results of $S_{1}$ from training data shown in Figure 8(b).

3.2. Modeling Method. In order to better present the correlation between $S_{\mathrm{I}, \mathrm{II}}$ and temperature field from training data, two steps are specifically carried out as follows: (1) temperature and temperature difference data from sufficient solar radiation days, whose daily variation trends 


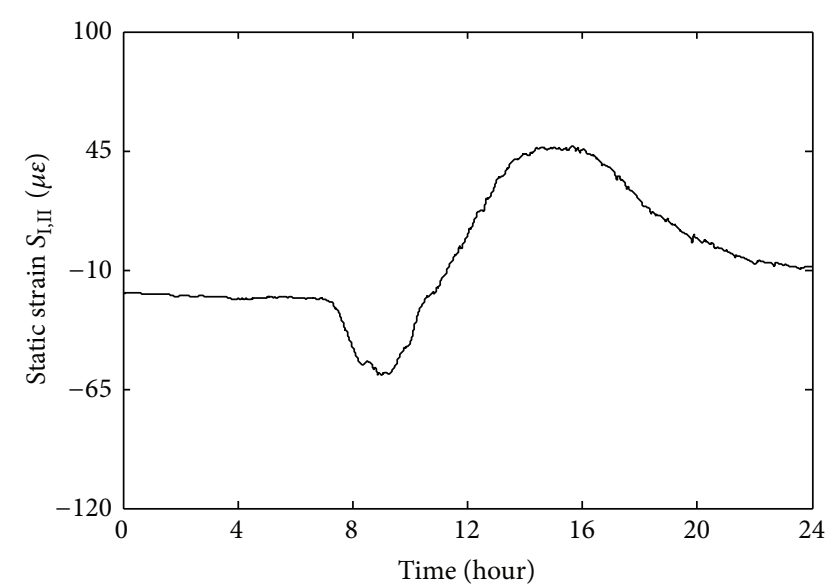

(a) Daily extraction result $S_{I, I I}$ of $S_{1}$

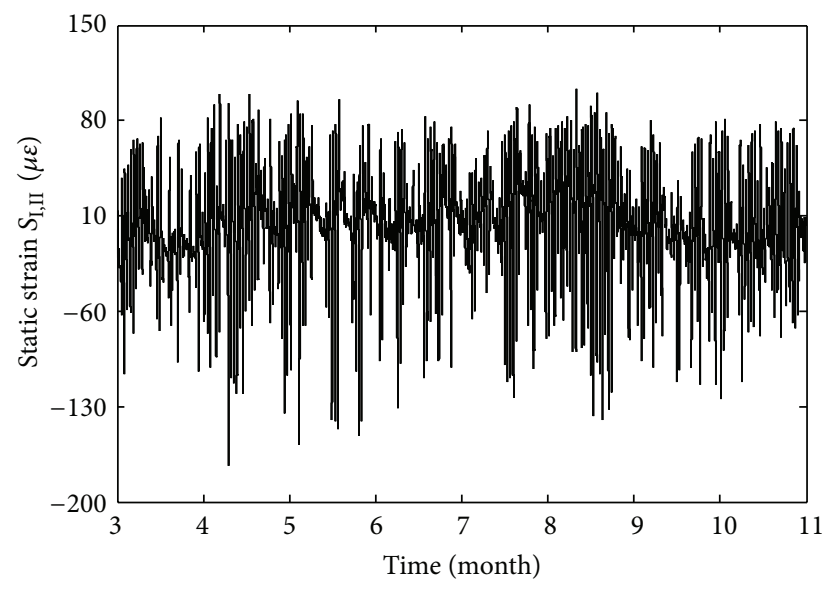

(b) Global extraction result $S_{\mathrm{I}, \mathrm{II}}$ of $S_{1}$

FIGURE 8: Extraction results $S_{\mathrm{I}, \mathrm{II}}$ of static strain data $S_{1}$.

are similar to one smooth single-period sine curve as shown in Figure 3(b) [12], are specially selected and then $S_{\mathrm{I}, \mathrm{II}}$ are selected from the same corresponding days; (2) daily maximum and minimum values are furthermore chosen from the selected temperature field and $S_{I, I I}$ data. The scatter plots between $S_{\mathrm{I}, \mathrm{II}}$ of $S_{1}$ and temperature difference $T_{12}$, between $S_{\mathrm{I}, \mathrm{II}}$ of $S_{2}$ and temperature $T_{1}$, are shown in Figures 9(a) and 9(b), respectively, both presenting apparent linear correlation. Moreover, considering that $S_{\text {IIII }}$ of each static strain data may be influenced by many temperature and temperature difference data, $S_{\mathrm{I}, \mathrm{II}}$ are expressed as follows:

$$
S_{\mathrm{I}, \mathrm{II}}=\sum_{i=1}^{8} \alpha_{i} T_{i}+\sum_{j=1}^{16} \beta_{j} D_{j}+c
$$

where $T_{i}$ is the $i$ th temperature data from set $\left\{T_{1}, T_{2}, T_{3}\right.$, $\left.T_{4}, T_{5}, T_{6}, T_{7}, T_{8}\right\}, D_{j}$ is the $j$ th temperature difference data from set $\left\{T_{12}, T_{34}, T_{56}, T_{78}, T_{13}, T_{15}, T_{17}, T_{35}, T_{37}, T_{57}, T_{24}\right.$, $\left.T_{26}, T_{28}, T_{46}, T_{48}, T_{68}\right\}, \alpha_{i}$ is the $i$ th linear expansion coefficient of $T_{i}, \beta_{j}$ is the $j$ th linear expansion coefficient of $T_{i j}$, and $c$ is the constant term.
Considering that total 24 linear expansion coefficients and one constant term are very complicated for calculation, principal component analysis is introduced to simplify (2). Generally speaking, principal components can be derived from either an algebraic or a geometric viewpoint. Given 8 random variables $\left\{T_{1}, T_{2}, T_{3}, T_{4}, T_{5}, T_{6}, T_{7}, T_{8}\right\}$ with a known covariance matrix $\sum$, the $k$ th $(k=1,2, \ldots, 8)$ principal component $P_{k}$ is a linear expression of the 8 random variables defined as follows $[13,14]$ :

$$
P_{k}=\sum_{j=1}^{8} u_{j k} T_{j}
$$

Starting from the maximization of variance of $P_{k}$ subjecting to $\vec{u}_{k}^{\prime} \vec{u}_{l}=0(l=1,2, \ldots, 8, l \neq k)$, the algebraic derivation turns out that $\vec{u}_{k}=\left(u_{1 k}, u_{2 k}, \ldots, u_{8 k}\right)^{\prime}$ is an eigenvector of $\sum$ corresponding to the $k$ th largest eigenvalue $\lambda_{k}$, referred to as principal component coefficients and principal component variances, respectively. After eigendecomposition of the covariance matrix $\sum, \vec{u}_{k}^{\prime}$ is obtained as follows:

$$
\left[\begin{array}{l}
\vec{u}_{1}^{\prime} \\
\vec{u}_{2}^{\prime} \\
\vec{u}_{3}^{\prime} \\
\vec{u}_{4}^{\prime} \\
\vec{u}_{5}^{\prime} \\
\vec{u}_{6}^{\prime} \\
\vec{u}_{7}^{\prime} \\
\vec{u}_{8}^{\prime}
\end{array}\right]=\left[\begin{array}{cccccccc}
0.319 & 0.384 & 0.364 & 0.382 & 0.358 & 0.387 & 0.333 & 0.289 \\
0.462 & -0.341 & -0.144 & -0.332 & 0.110 & -0.365 & 0.333 & 0.531 \\
-0.486 & 0.177 & -0.459 & -0.363 & 0.110 & 0.461 & 0.238 & 0.330 \\
-0.211 & -0.628 & 0.262 & -0.060 & 0.641 & 0.213 & -0.167 & -0.068 \\
0.491 & 0.301 & -0.335 & -0.367 & 0.420 & 0.103 & -0.229 & 0.427 \\
-0.138 & -0.094 & -0.209 & 0.205 & 0.174 & -0.212 & 0.739 & -0.514 \\
0.267 & -0.367 & -0.580 & 0.551 & -0.125 & 0.336 & -0.142 & 0.065 \\
-0.269 & 0.275 & -0.274 & 0.358 & 0.463 & -0.539 & -0.271 & 0.264
\end{array}\right] ;
$$




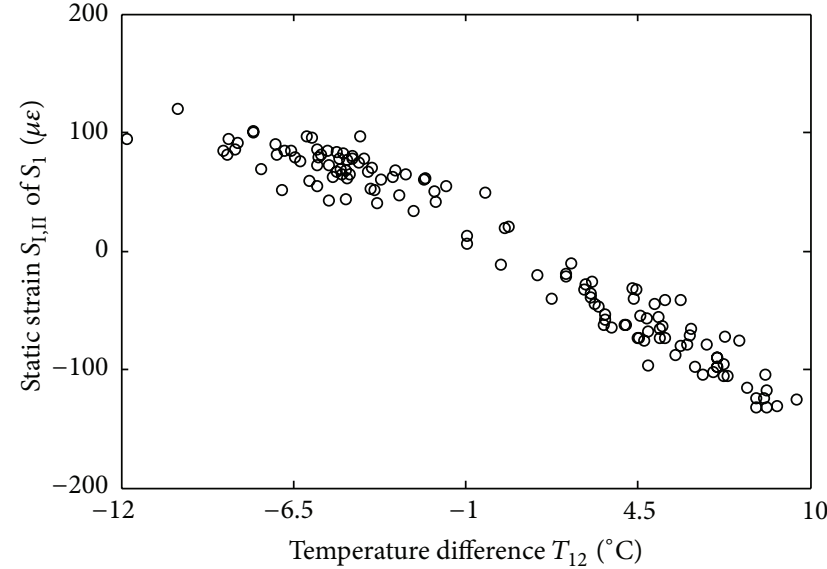

(a) $S_{\text {I,II }}$ of $S_{1}$ and temperature difference $T_{12}$

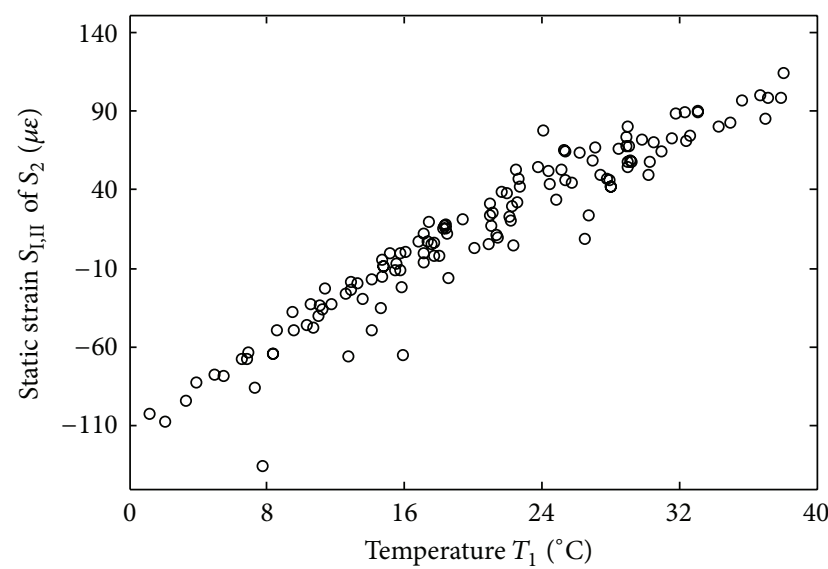

(b) $S_{\text {I,II }}$ of $S_{2}$ and temperature $T_{1}$

FIGURE 9: Correlation scatter plots between $S_{I, I I}$ and temperature and temperature difference.

according to the Pareto diagram of explained variances of $P_{k}$ shown in Figure 10(a), it can be seen that the explained variance of $P_{1}$ is $96.7 \%$, very higher than the other principal components, so $P_{1}$ is specially selected with its calculation equation as follows:

$$
P_{1}=\vec{u}_{1}^{\prime} T
$$

where $T=\left[T_{1}, T_{2}, T_{3}, T_{4}, T_{5}, T_{6}, T_{7}, T_{8}\right]^{\prime}$. Moreover, the principal components $R_{m}(m=1,2, \ldots, 16)$ of 16 random variables $\left\{T_{12}, T_{34}, T_{56}, T_{78}, T_{13}, T_{15}, T_{17}, T_{35}, T_{37}, T_{57}, T_{24}, T_{26}\right.$, $\left.T_{28}, T_{46}, T_{48}, T_{68}\right\}$ are obtained through eigendecomposition of covariance matrix $[13,14]$, with the Pareto diagram of their

$$
\left[\begin{array}{c}
\vec{v}_{1}^{\prime} \\
\vec{v}_{2}^{\prime} \\
\vec{v}_{3}^{\prime}
\end{array}\right]
$$

$$
=\left[\begin{array}{cccccccc}
0.403 & 0.209 & 0.234 & -0.108 & -0.248 & 0.245 & 0.289 & 0.177 \\
0.369 & 0.119 & 0.239 & 0.088 & 0.385 & 0.299 & 0.311 & 0.019 \\
0.386 & 0.272 & 0.310 & -0.144 & -0.055 & -0.140 & -0.167 & -0.341
\end{array}\right.
$$

$\begin{array}{lllll}0.308 & 0.208 & -0.188 & -0.077 & 0.288\end{array}$

$\begin{array}{lllll}-0.275 & 0.159 & 0.076 & -0.317 & -0.078\end{array}$
$D=\left[T_{12}, T_{34}, T_{56}, T_{78}, T_{13}, T_{15}, T_{17}, T_{35}, T_{37}, T_{57}, T_{24}, T_{26}, T_{28}\right.$, $\left.T_{46}, T_{48}, T_{68}\right]$. Therefore, the calculation of $S_{\text {I,II }}$ can be simplified as follows:

$$
S_{\mathrm{I}, \mathrm{II}}=\lambda_{1} P_{1}+\vec{\gamma}_{1 \times 3} \vec{R}_{3 \times 1}+c,
$$

where $\lambda_{1}$ is performance parameter of $P_{1}$ and $\vec{\gamma}_{1 \times 3}$ is one vector containing three performance parameters corresponding to $\vec{R}_{3 \times 1}\left(\vec{\gamma}_{1 \times 3}=\left[\gamma_{1}, \gamma_{2}, \gamma_{3}\right]\right.$ and $\vec{R}_{3 \times 1}=\left[R_{1}, R_{2}, R_{3}\right]^{\prime}$ specifically). The values of performance parameters $\lambda_{1}, \vec{\gamma}_{1 \times 3}$, and $c$ can be estimated by multivariate linear regression $\begin{array}{llllll}0.019 & 0.019 & -0.019 & 0.167 & -0.347\end{array}$

0.148

$\left.\begin{array}{lll}0.184 & -0.232 & -0.461\end{array}\right]$

where $\vec{v}_{n}^{\prime}=\left(v_{1 n}, v_{2 n}, \ldots, v_{16 n}\right)(n=1,2,3)$ is an eigenvector of covariance matrix and their values are

explained variances shown in Figure 10(b). It can be seen that sum of explained variances of $R_{1}, R_{2}$, and $R_{3}$ is $98.8 \%$, equations as follows:

$$
\left[\begin{array}{l}
R_{1} \\
R_{2} \\
R_{3}
\end{array}\right]=\left[\begin{array}{c}
\vec{v}_{1}^{\prime} \\
\vec{v}_{2}^{\prime} \\
\vec{v}_{3}^{\prime}
\end{array}\right] D
$$

method [15], and then the correlation models between $S_{\mathrm{I}, \mathrm{II}}$ and temperature field can be expressed as follows:

$$
S_{\mathrm{I}, \mathrm{II}}=\lambda_{1}\left(\vec{u}_{1}^{\prime} T\right)+\vec{\gamma}_{1 \times 3}\left(\left[\begin{array}{c}
\vec{v}_{1}^{\prime} \\
\vec{v}_{2}^{\prime} \\
\vec{v}_{3}^{\prime}
\end{array}\right] D\right)+c .
$$

3.3. Modeling Results and Effectiveness Verification. Based on the modeling method above, the correlation between $S_{\text {IIII }}$ of each static strain data and temperature field is modeled by (9) using training data, with corresponding performance 


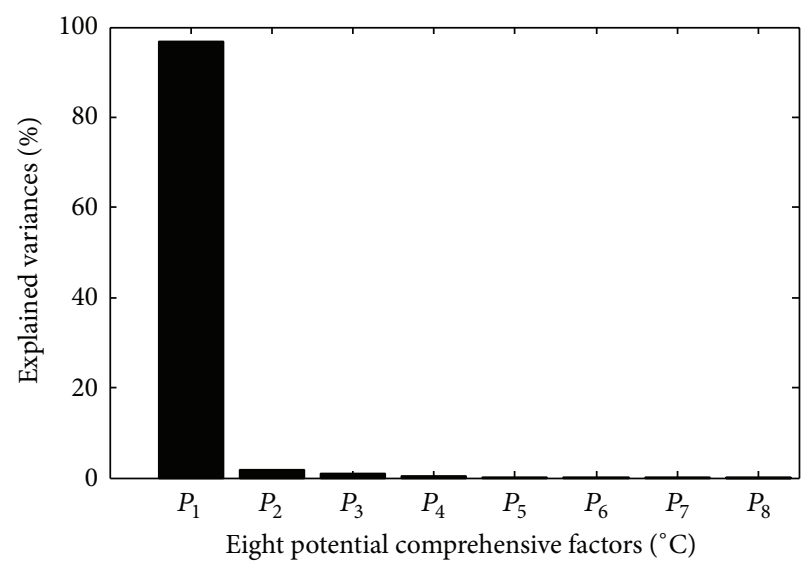

(a) Temperature data

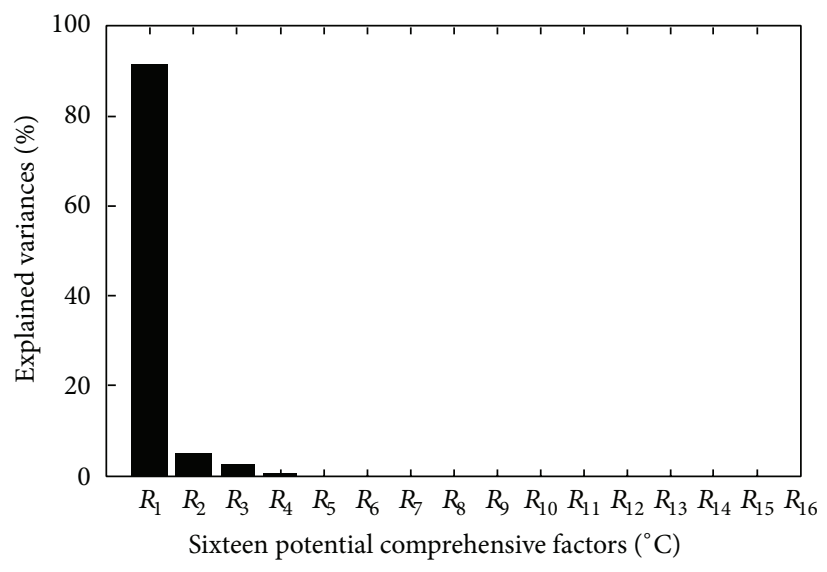

(b) Temperature difference data

FIGURE 10: Pareto diagram of explained variances of temperature and temperature difference data.

TABLE 1: Performance parameter values $\lambda_{1}, \gamma_{1}, \gamma_{2}, \gamma_{3}$, and $c$ of correlation models.

\begin{tabular}{lccccc}
\hline \multirow{2}{*}{ Static strain data } & \multicolumn{5}{c}{ Weighted values of correlation models } \\
& $\lambda_{1}$ & $\gamma_{1}$ & $\gamma_{2}$ & $\gamma_{3}$ & $c$ \\
\hline$S_{\mathrm{I}, \mathrm{II}}$ of $S_{1}$ & 0.454 & -4.711 & -2.597 & -4.944 & -46.806 \\
$S_{\mathrm{I}, \mathrm{II}}$ of $S_{2}$ & 1.585 & 0.013 & 4.104 & -1.247 & -70.238 \\
$S_{\mathrm{I}, \mathrm{II}}$ of $S_{3}$ & 0.301 & 3.416 & -2.098 & 2.968 & -6.884 \\
$S_{\mathrm{I}, \mathrm{II}}$ of $S_{4}$ & 0.350 & -0.734 & 0.351 & 0.948 & -23.597 \\
$S_{\mathrm{I}, \mathrm{II}}$ of $S_{5}$ & 0.179 & -4.219 & 1.827 & 3.165 & -22.049 \\
$S_{\mathrm{I}, \mathrm{II}}$ of $S_{6}$ & 0.062 & -3.245 & 8.242 & -5.398 & -22.862 \\
$S_{\mathrm{I}, \mathrm{II}}$ of $S_{7}$ & -0.367 & 2.411 & -0.598 & 5.531 & 17.075 \\
$S_{\mathrm{I}, \mathrm{II}}$ of $S_{8}$ & 0.611 & 2.188 & -1.130 & 2.018 & -32.799 \\
\hline
\end{tabular}

parameter values $\lambda_{1}, \gamma_{1}, \gamma_{2}, \gamma_{3}$, and $c$ shown in Table 1 . In order to test the modeling effectiveness of the correlation models, temperature and temperature difference data from test data are substituted into (9) to calculate simulative $S_{\mathrm{I}, \mathrm{II}}$ after two-step analysis (detailed in Section 3.2), and then the scattered points between simulative $S_{\mathrm{I}, \mathrm{II}}$ and monitoring $S_{\text {IIII }}$ are plotted as shown in Figures 11(a) 11(f), all of which present good linear correlation. Therefore, the scattered points are furthermore least-square fitted by linear function:

$$
S_{s}=k S_{m}+b,
$$

where $S_{s}$ denotes simulative $S_{\mathrm{I}, \mathrm{II}}, S_{m}$ denotes monitoring $S_{\mathrm{I}, \mathrm{II}}$, and $k, b$ are fitting parameters, with the fitting results shown in Figures 11(a) 11(f) as well. The fitting results show that all the fitting curves can well describe the linear correlation of scattered points with $k$ close to 1 and $b$ close to 0 , verifying good modeling effectiveness of the correlation models.

\section{Static Performance Assessment}

4.1. Assessment Method. Daily maximum and minimum values of temperature and temperature difference from training data are substituted into (9) to calculate simulative $S_{\text {I,II }}$ and then residual static strains are obtained by simulative $S_{\text {I,II }}$ minus monitoring $S_{\mathrm{I}, \mathrm{II}}$. Augmented Dickey-Fuller test at nominal significance level of 0.05 indicates that time history of residual static strains is one stationary stochastic process around the central line of $0 \mu \varepsilon$ and within the scope of upper and lower limit $[-50 \mu \varepsilon, 50 \mu \varepsilon]$, such as that of $S_{1}$ shown in Figure 12(a), which are considered relative initial state of static performance of Dashengguan Yangtze Bridge.

In order to investigate change regulations of residual static strains under performance degradation, performance parameters $\lambda_{1}$ and $\vec{\gamma}_{1 \times 3}$ in (9) are assumed to increase by $20 \%$ each month (20\% is an appropriate value to clearly reveal the change regulations of residual static strains under performance degradation), with 3 kinds of possible combinations specifically as follows: (1) only $\lambda_{1}$ increases by $20 \%$; (2) only $\vec{\gamma}_{1 \times 3}$ increases by $20 \%$; (3) both $\lambda_{1}$ and $\vec{\gamma}_{1 \times 3}$ increase by $20 \%$. Then residual static strains of $S_{1}$ for each combination are calculated as shown in Figures 12(b) 12(d) respectively, from which three kinds of degradation regulations can be obtained: (1) residual static strains of $S_{1}$ from the first combination gradually deviate from the central line with time and then surpass the upper limit; (2) residual static strains of $S_{1}$ from the second combination fluctuate more fiercely with time around the central line and then surpass the upper and lower limit; (3) residual static strains of $S_{1}$ from the third combination can be considered the summation of the first and second situations. Therefore, the degradation of static performance can be confirmed if one of the degradation regulations exits in time history of residual static strains.

4.2. Assessment Results. Using the analytical method above, daily maximum and minimum values of temperature and temperature difference from assessment data are substituted into (9) to calculate simulative $S_{\text {I,II }}$ and then residual static strains of each static strain data are acquired by simulative $S_{\text {I,II }}$ minus monitoring $S_{\text {I,II }}$ as shown in Figures 13(a) 13(f) respectively. Through analysis of their change trends, all of the residual static strains do not obviously present any 


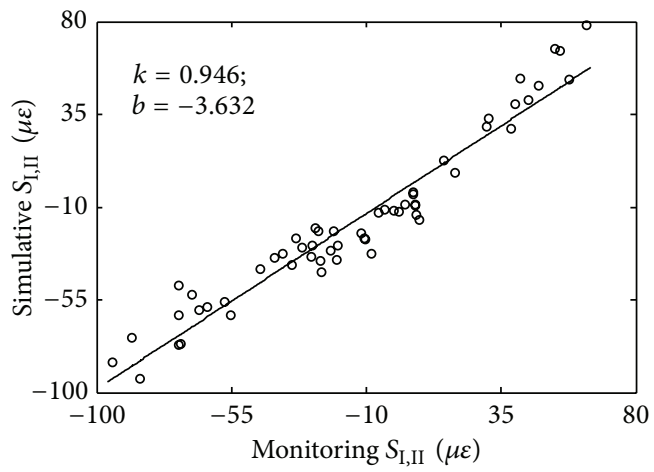

(a) $S_{1}$

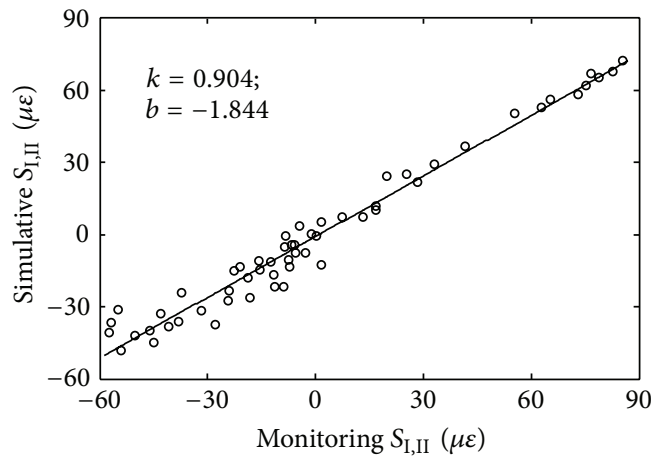

(c) $S_{3}$

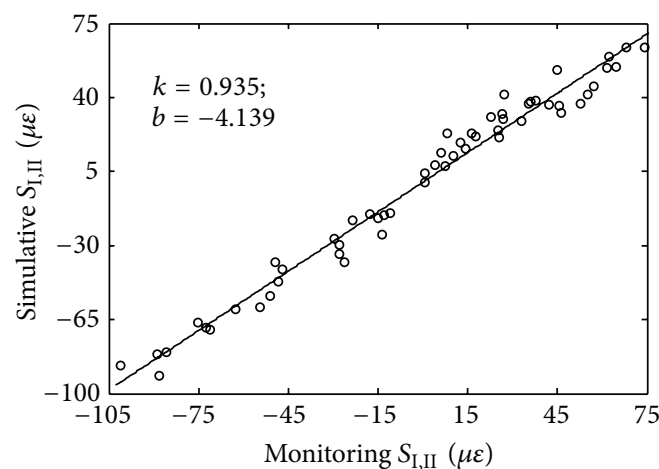

(e) $S_{5}$

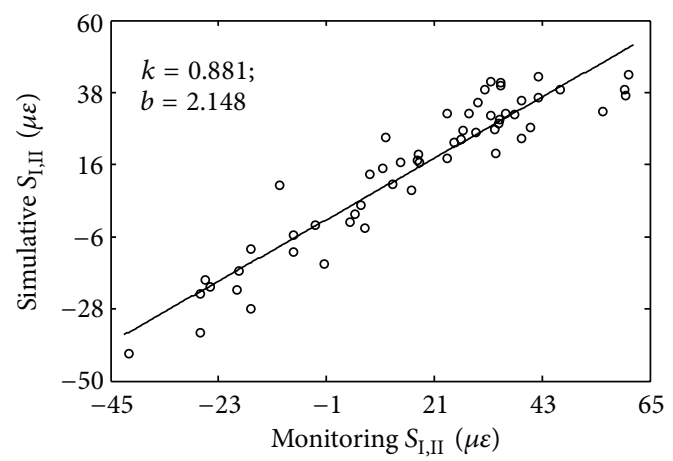

- Scattered points

— Fitting curve

(g) $S_{7}$

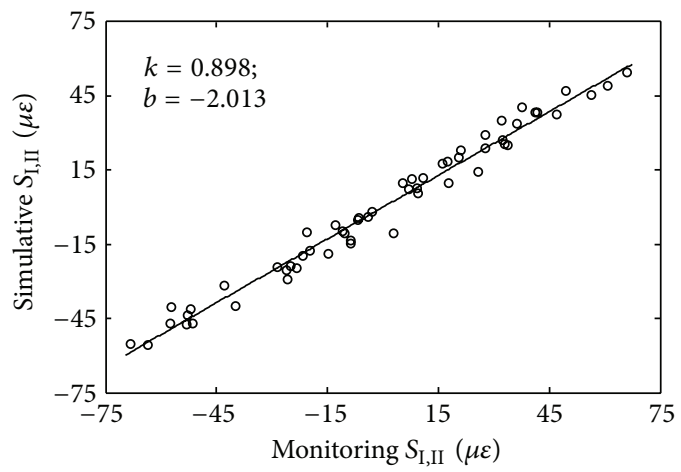

(b) $S_{2}$

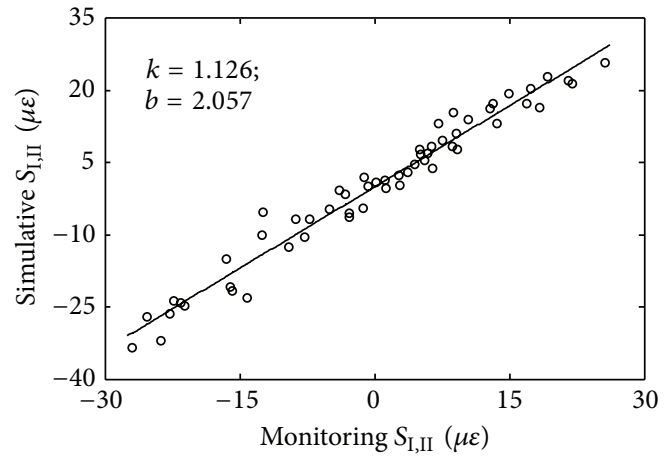

(d) $S_{4}$

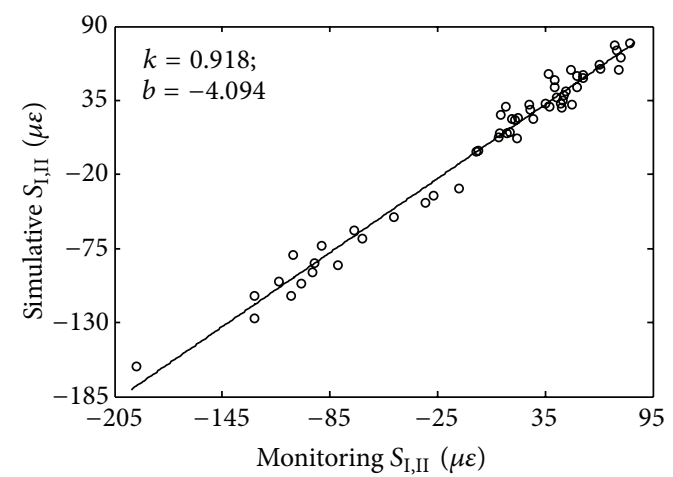

(f) $S_{6}$

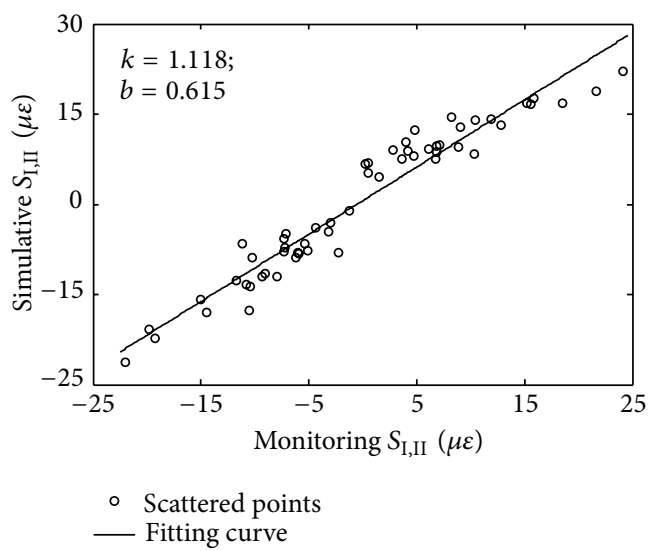

(h) $S_{8}$

FIGURE 11: Correlation between simulative $S_{\mathrm{I}, \mathrm{II}}$ and monitoring $S_{\mathrm{I}, \mathrm{II}}$. 


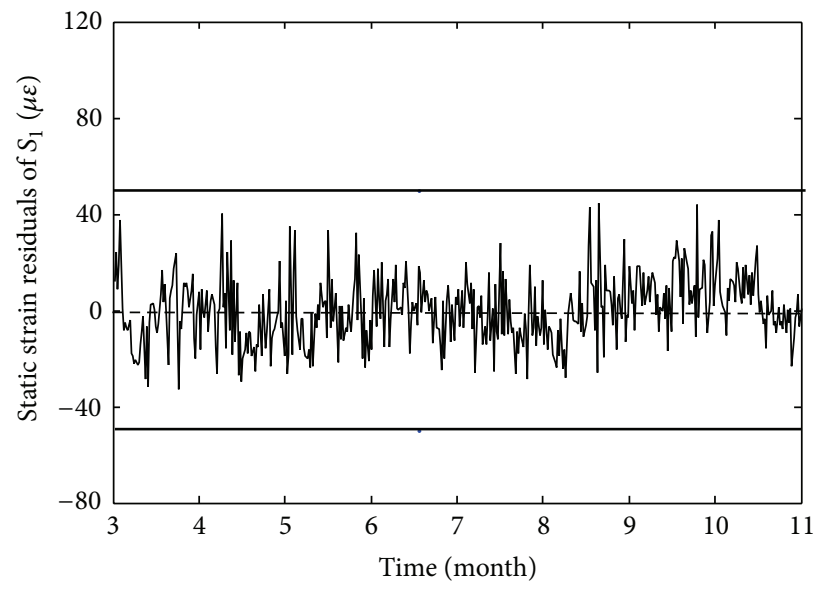

(a) Relative initial state of static performance

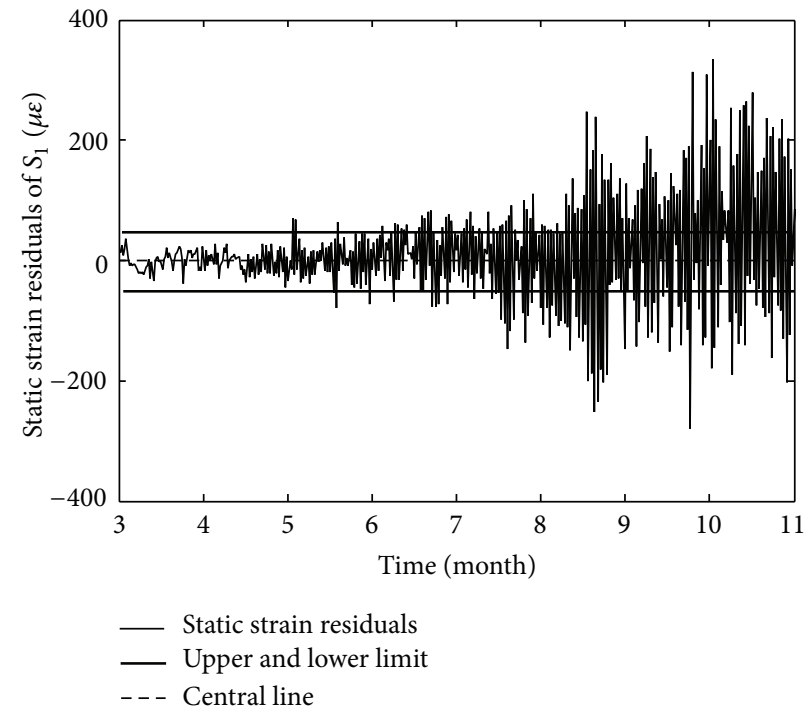

(c) $\vec{\gamma}_{1 \times 3}$ increases by $20 \%$

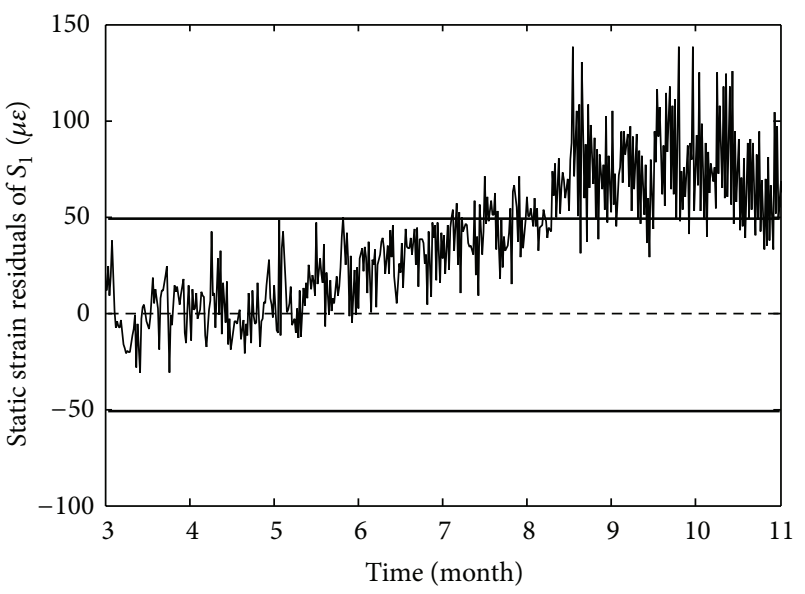

(b) $\lambda_{1}$ increases by $20 \%$

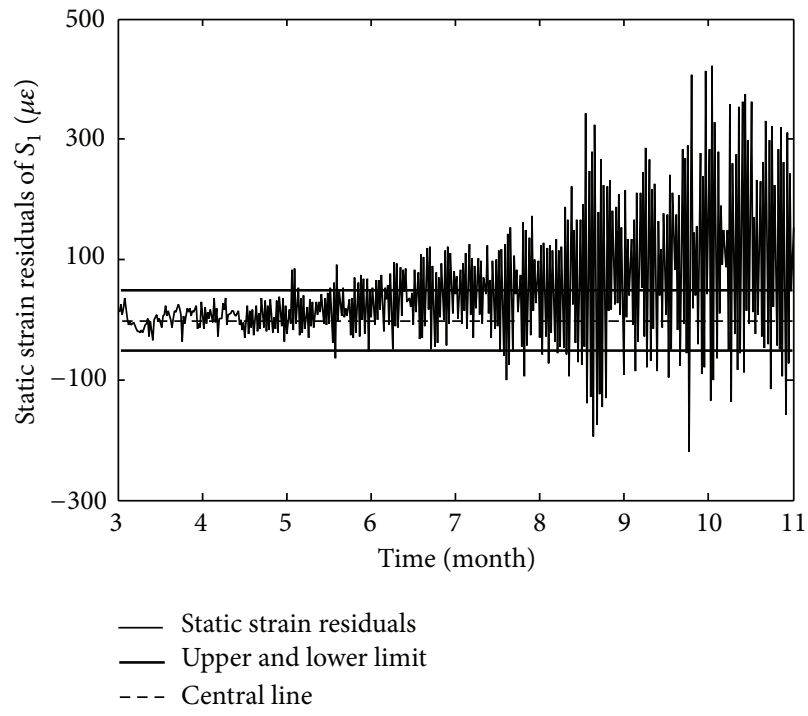

(d) $\lambda_{1}$ and $\vec{\gamma}_{1 \times 3}$ increase by $20 \%$

FIGURE 12: Relative initial state and degradation state of static performance.

kind of the degradation regulations, indicating that the static performance of Dashengguan Yangtze Bridge was in a good condition during that period.

\section{Conclusions}

Based on correlation between temperature field and its static strain, static performance of Dashengguan Yangtze Bridge is assessed by using methods such as wavelet packet decomposition, multivariate linear regression modeling, principal component analysis, and residual strain analysis. After the investigation, some conclusions can be drawn as follows.

(1) Static strain data mainly contains three parts: static strain I caused by temperature, static strain II caused by temperature difference, and static strain III caused by train. The influence proportion of train in static strain data is obviously lower than temperature and temperature difference.
(2) Wavelet packet decomposition method can effectively extract $S_{\mathrm{I}, \mathrm{II}}$ and remove sharp peaks caused by trains as well; principal component analysis can effectively simplify the multivariate linear regression models between $S_{\mathrm{I}, \mathrm{II}}$ and temperature field; fitting parameters of linear functions verify good modeling effectiveness of multivariate linear correlation models.

(3) Three kinds of degradation regulations of static performance are put forward to assess static performance of Dashengguan Yangtze Bridge, and the results show that residual static strains of all static strain data do not obviously present any kind of the degradation regulations, indicating that the static performance of Dashengguan Yangtze Bridge was in a good condition during that period.

What should to be mentioned is that the conclusions above are based on the monitoring data in certain period. However, the static performance degradation behavior of 


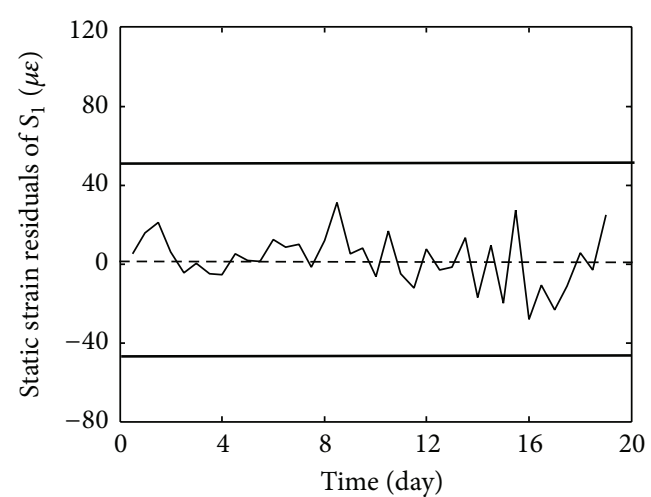

(a) Residual static strains of $S_{1}$

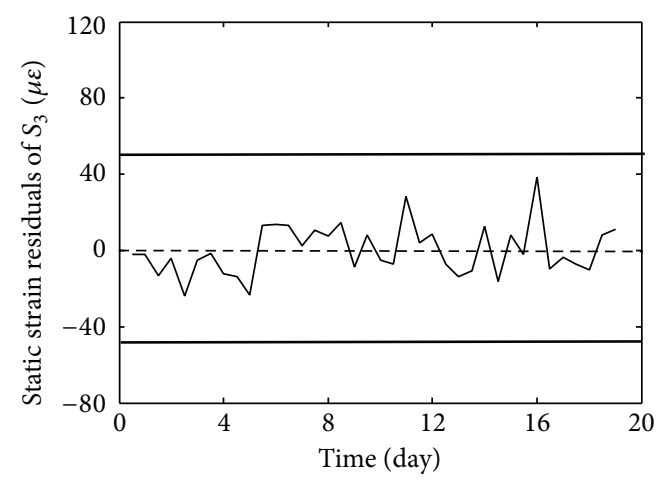

(c) Residual static strains of $S_{3}$

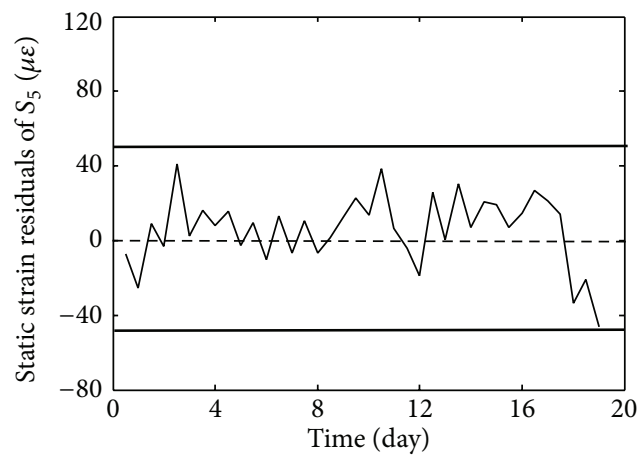

(e) Residual static strains of $S_{5}$

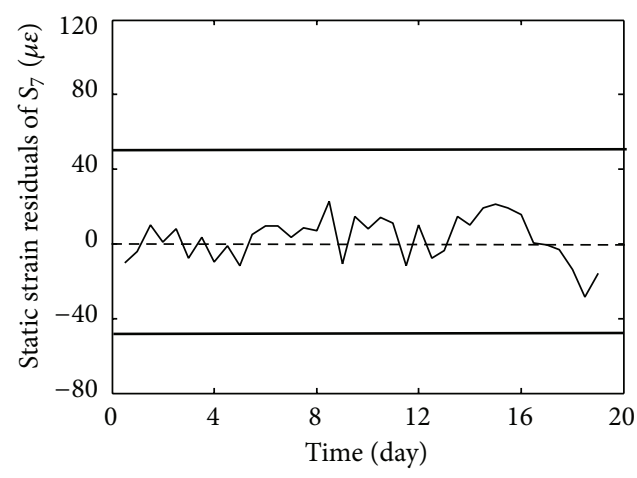

_ Static strain residuals
_ Upper and lower limit
_ - Central line

(g) Residual static strains of $S_{7}$

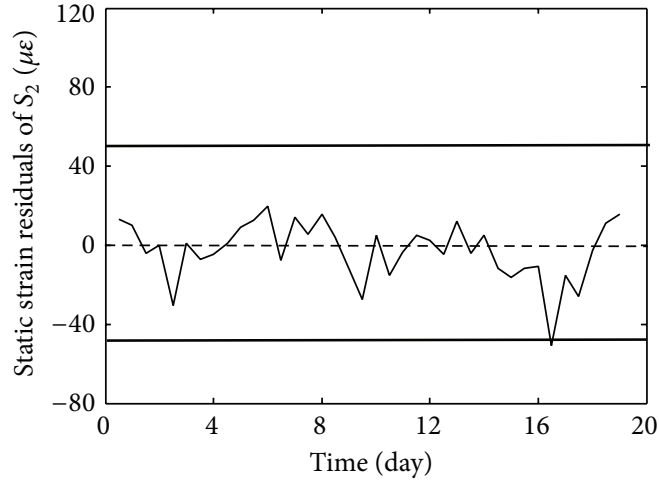

(b) Residual static strains of $S_{2}$

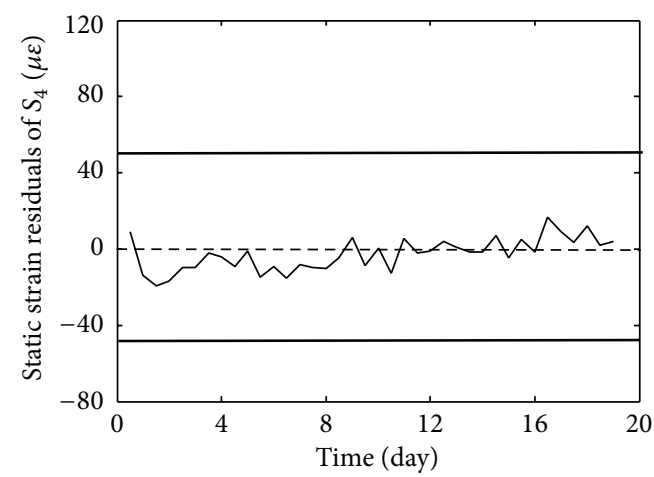

(d) Residual static strains of $S_{4}$

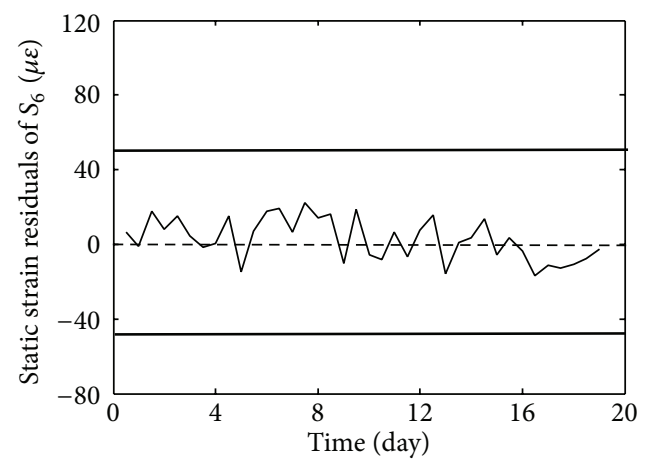

(f) Residual static strains of $S_{6}$

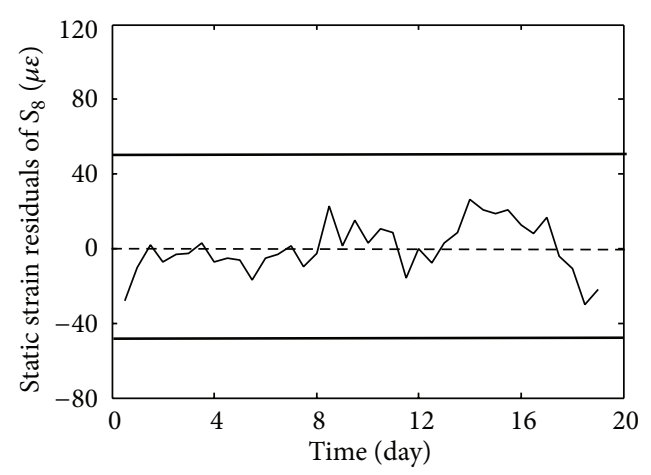

_ Static strain residuals
_ Upper and lower limit

(h) Residual static strains of $S_{8}$

FIGURE 13: Time histories of residual static strains for each static strain data. 
bridge structures is a very slow process; therefore static performance assessment of Dashengguan Yangtze Bridge should be further analyzed by the accumulation of long-term measurement.

\section{Conflict of Interests}

The authors declare that there is no conflict of interests regarding the publication of this paper.

\section{Acknowledgments}

The authors gratefully acknowledge the National Science and Technology Support Program (no. 2014BAG07B01), the National Natural Science Foundation (no. 51178100), the Fundamental Research Funds for the Central Universities and the Innovation Plan Program for Ordinary University Graduates of Jiangsu Province in 2014 (no. KYLX_0156), the Scientific Research Foundation of Graduate School of Southeast University (no. YBJJ1441), and Key Program of Ministry of Transport (no. 2011318223190 and no. 2013319223120).

\section{References}

[1] T. H. Yi, H. N. Li, and X. D. Zhang, "Sensor placement on Canton Tower for health monitoring using asynchronousclimbing monkey algorithm," Smart Materials and Structures, vol. 21, no. 12, pp. 1-12, 2012.

[2] T.-H. Yi, H.-N. Li, and M. Gu, "Recent research and applications of GPS-based monitoring technology for high-rise structures," Structural Control and Health Monitoring, vol. 20, no. 5, pp. 649670, 2013.

[3] R. Regier and N. A. Hoult, "Distributed strain monitoring for bridges: temperature effects," in Sensors and Smart Structures Technologies for Civil, Mechanical, and Aerospace Systems, vol. 9061 of Proceedings of SPIE, San Diego, Calif, USA, March 2014.

[4] M. Gul, H. B. Gokce, and F. N. Catbas, "A characterization of traffic and temperature induced strains acquired using a bridge monitoring system," in Proceedings of the 2011 Structures Congress, pp. 89-100, April 2011.

[5] M. Li, W.-X. Ren, Y.-D. Hu, and N.-B. Wang, "Separating temperature effect from dynamic strain measurements of a bridge based on analytical mode decomposition method," Journal of Vibration and Shock, vol. 31, no. 21, pp. 6-29, 2012 (Chinese).

[6] A. Bueno, B. D. Torres, P. Calderon, and S. Sales, "Monitoring of a steel incrementally launched bridge construction with strain and temperature FBGs sensors," in Optical Sensing and Detection, 772620, vol. 7726 of Proceedings of SPIE, Brussels, Belgium, April 2010.

[7] B. Gu, Z.-J. Chen, and X.-D. Chen, "Analysis of measured effective temperature and strains of long-span concrete box girder bridge," Journal of Jilin University: Engineering and Technology Edition, vol. 43, no. 4, pp. 877-884, 2013 (Chinese).

[8] Y.-F. Duan, Y. Li, and Y.-Q. Xiang, "Strain-temperature correlation analysis of a tied arch bridge using monitoring data," in Proceedings of the 2nd International Conference on Multimedia Technology (ICMT '11), pp. 6025-6028, July 2011.

[9] S. Li, H. Li, J. Ou, and H. Li, "Integrity strain response analysis of a long span cable-stayed bridge," Key Engineering Materials, vol. 413-414, pp. 775-783, 2009.
[10] T. Figlus, Š. Liščák, A. Wilk, and B. Łazarz, "Condition monitoring of engine timing system by using wavelet packet decomposition of a acoustic signal," Journal of Mechanical Science and Technology, vol. 28, no. 5, pp. 1663-1671, 2014.

[11] R. Wald, T. M. Khoshgoftaar, and J. C. Sloan, "Feature selection for optimization of wavelet packet decomposition in reliability analysis of systems," International Journal on Artificial Intelligence Tools, vol. 22, no. 5, Article ID 1360011, 2013.

[12] Y.-L. Ding and G.-X. Wang, "Estimating extreme temperature differences in steel box girder using long-term measurement data," Journal of Central South University, vol. 20, no. 9, pp. 25372545,2013

[13] H. W. Wang, R. Guan, and J. J. Wu, "Complete-informationbased principal component analysis for interval-valued data," Neurocomputing, vol. 86, pp. 158-169, 2012.

[14] A. Singh, S. Datta, and S. S. Mahapatra, "Principal component analysis and fuzzy embedded Taguchi approach for multiresponse optimization in machining of GFRP polyester composites: a case study," International Journal of Industrial and Systems Engineering, vol. 14, no. 2, pp. 175-206, 2013.

[15] A. Amiri, A. Saghaei, M. Mohseni, and Y. Zerehsaz, "Diagnosis aids in multivariate multiple linear regression profiles monitoring," Communications in Statistics. Theory and Methods, vol. 43, no. 14, pp. 3057-3079, 2014. 


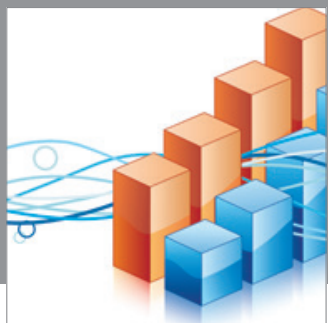

Advances in

Operations Research

mansans

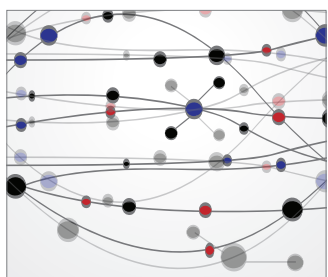

The Scientific World Journal
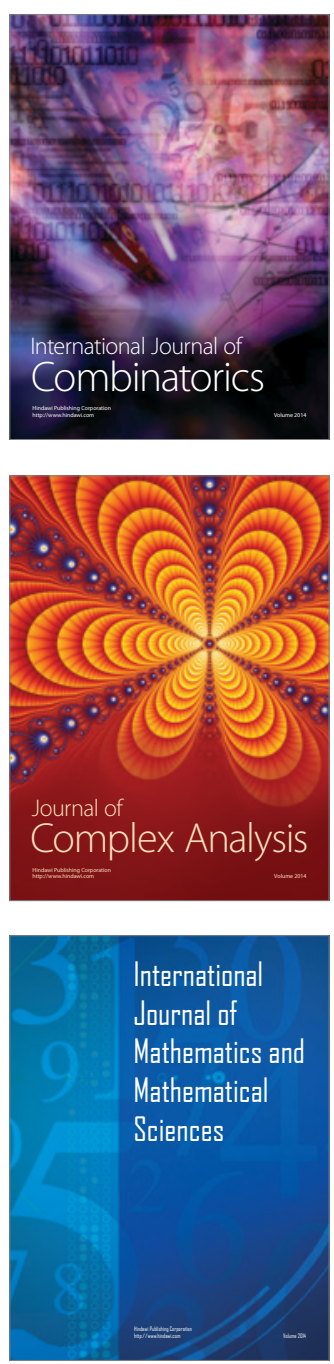
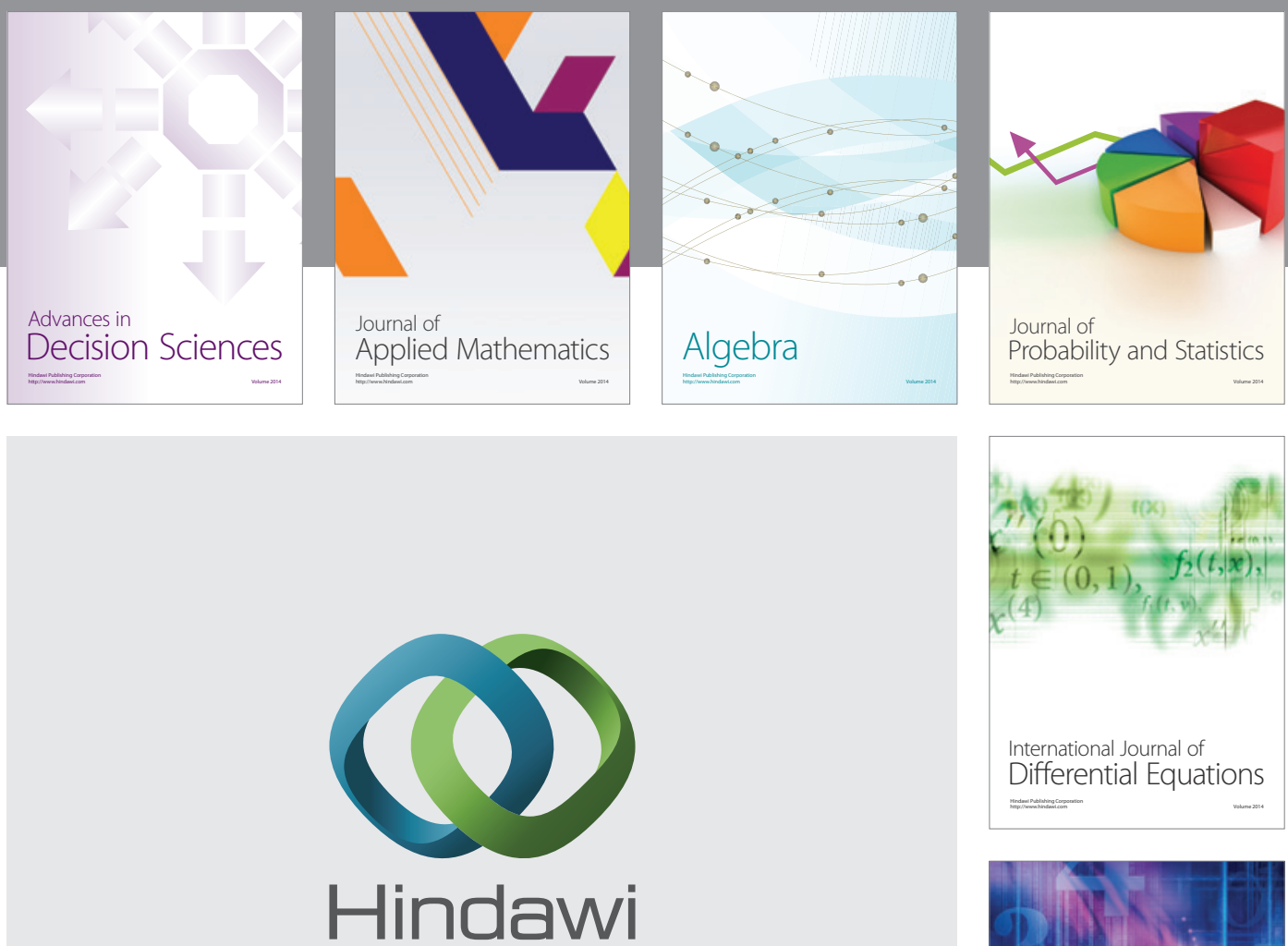

Submit your manuscripts at http://www.hindawi.com
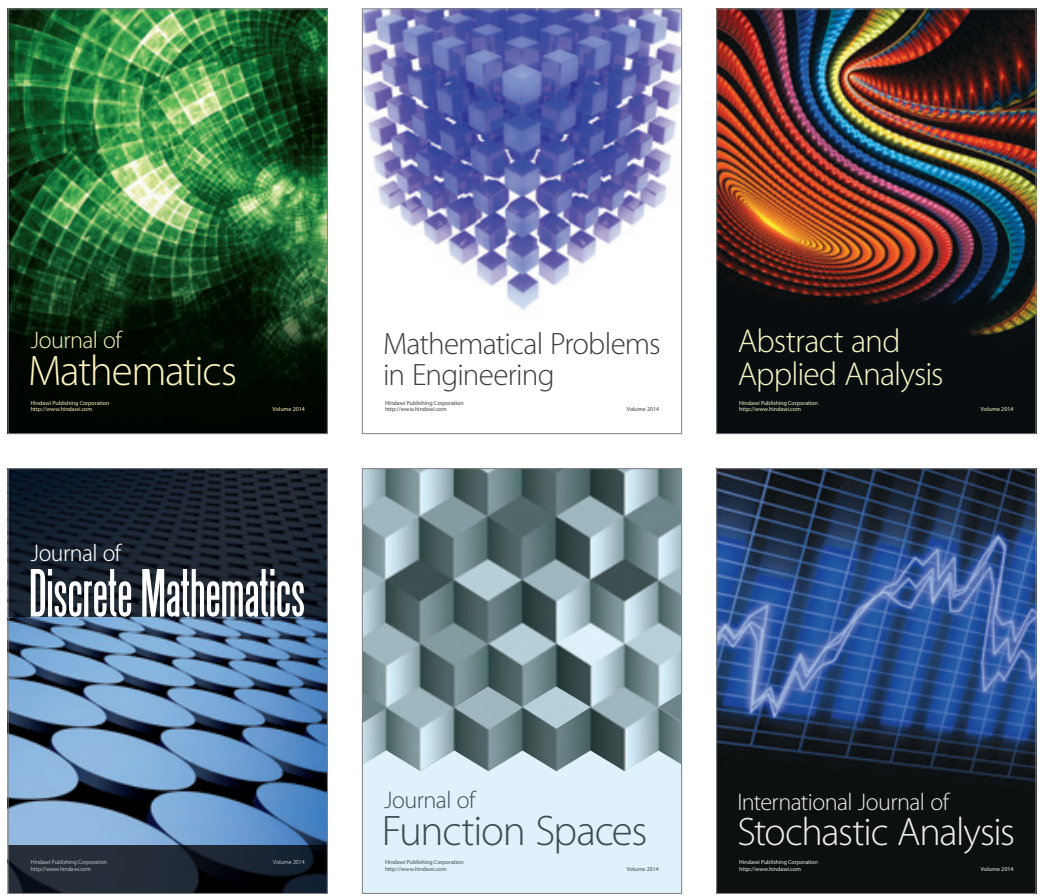

Journal of

Function Spaces

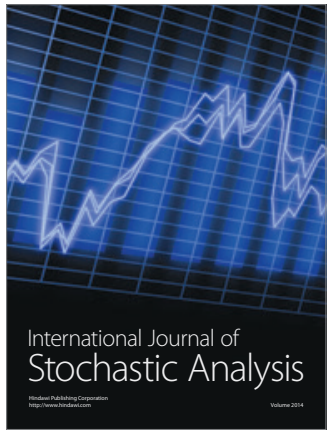

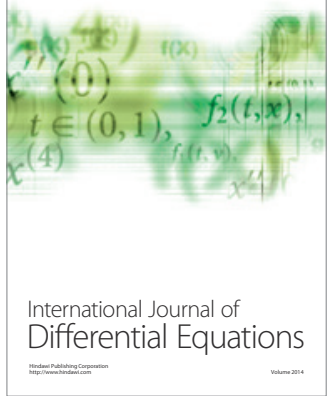
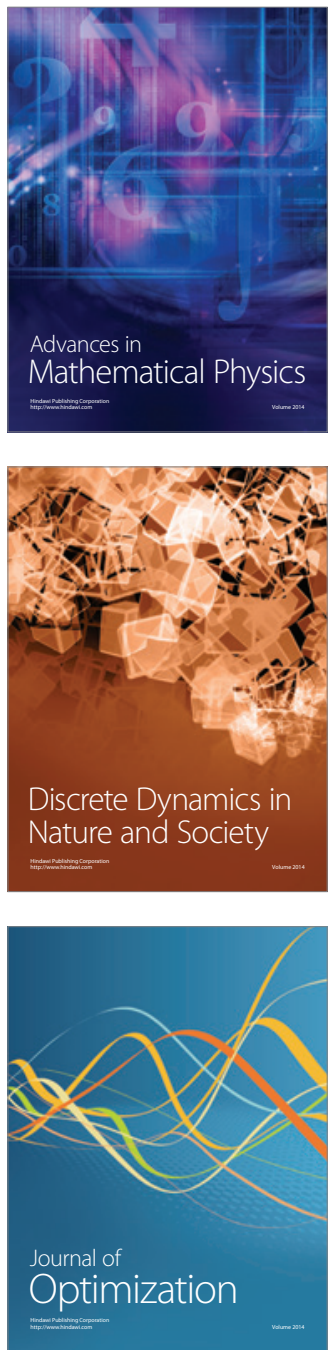